\title{
Personality Disorders, Types of Violence, and Stress Responses in Female Who Perpetrate Intimate Partner Violence
}

\author{
Alicia Spidel $^{1}$, Caroline Greaves ${ }^{2,3}$, Tonia L. Nicholls ${ }^{2,3}$, Julie Goldenson ${ }^{4}$, \\ Donald G. Dutton ${ }^{2}$ \\ ${ }^{1}$ University of Montreal, Montreal, Canada \\ ${ }^{2}$ University of British Columbia, Vancouver, Canada \\ ${ }^{3}$ British Columbia Mental Health and Addiction Services, Vancouver, Canada \\ ${ }^{4}$ Adler School of Professional Psychology, Toronto, Canada \\ Email: aliciaspidel@aim.com
}

Received July $1^{\text {st }}$, 2013; revised August 5 $5^{\text {th }}$, 2013; accepted September $2^{\text {nd }}, 2013$

\begin{abstract}
Copyright (c) 2013 Alicia Spidel et al. This is an open access article distributed under the Creative Commons Attribution License, which permits unrestricted use, distribution, and reproduction in any medium, provided the original work is properly cited.
\end{abstract}

\begin{abstract}
Few studies have examined characteristics and correlates of females who display assaultive behaviours towards their intimate partners. Personality disorders, anger responses, type of violence perpetrated, and post-traumatic stress reactions in female perpetrated intimate violence are important factors in diagnosis, management, and treatment considerations. The present study examined the incidence of cluster B personality disorder traits in a non-clinical sample of self-identified females who perpetrate intimate partner violence (IPV). Results suggest differences in anger responses, nature and severity of violence perpetrated, and post-traumatic stress reactions across personality disorder categories. The numerous important applied implications and future research directions are discussed.
\end{abstract}

Keywords: Trauma; Interpersonal Violence; Personality; Violence

\section{Introduction}

To date, the empirical study of female intimate partner violence has not been the subject of comparable consideration afforded to male intimate partner violence. Historically, investigations into partner violence have by and large focused on the male aggressor. These studies have generally progressed from identifying a pervasive and problematic behaviour, via examination of the types and frequencies of specific aggressive behaviours, to the current trend of batterer categorization based in part on the identification of certain predisposing personality features (see Dutton, 2002). The role, if any, of the female partner in these investigations has been to provide information regarding the violence, or to act as a secondary source to either substantiate or refute the male batterer's claims. The existence of long-standing societal misperceptions and varied political forces has meant that the occurrence of female perpetrated intimate partner violence (IPV) has largely gone unnoticed (see Dutton, Nicholls, \& Spidel, 2005; Hamel \& Nicholls, 2007; Spidel, Nicholls, Greaves, Goldenson \& Dutton, in press). Yet that women do engage in IPV has been increasingly well documented in several articles over the past few decades (e.g., Dutton \& Nicholls, 2005; Steinmetz, 1977-1978; Straus \& Gelles, 1990), as having similar perpetration rates to males (e.g., O’Keefe, Brockopp, \& Chew, 1986; Straus, 1999) and, in fact, some studies have reported greater violence severity (e.g., Magdol et al., 1997; Thompson, 1991).

More recently, Desmarais, Reeves, Nicholls, Telford, and Fiebert (2012a) completed a systematic review which examined research published over the course of the prior 10 years regarding the prevalence of physical IPV perpetrated by men and women in heterosexual relationships. Literature searches were undertaken in 3 databases (PubMed, PsycINFO, and Web of Science), yielding 750 articles published between 2000 and 2010. Of these, 111 articles reported rates of physical IPV perpetration in their review and found that the majority of studies were conducted in the United States and that most measured IPV using a Conflict Tactics Scale. These researchers calculated pooled prevalence estimates for female and male perpetration overall, and also by sample type, country, measurement time frame, and measurement approach. Across studies, the overall pooled prevalence estimate was $24.8 \%$ prevalence of physical IPV perpetrated by men and women. As had been found in previous reviews, prevalence was slightly higher for female- compared to male-perpetrated physical IPV. These researchers found that more than 1 in 4 women (28.3\%) and 1 in 5 men (21.6\%) reported perpetrating physical violence in an intimate relationship.

Clift and Dutton (2011) also found high rates of female perpetrated violence in Canadian undergraduate sample. These researchers used the Psychological Maltreatment Inventory (PMI) to look at the two subscales: 1) Dominance-Isolation (DI) tactics and 2) Emotional-Verbal (EV) abuse. An astonishing, 95.4\% of the women reported that they had perpetrated some form of EV abuse in the last year of their relationship, and $84.9 \%$ of this population had used some form or DI tactic during that period. Women were significantly more likely to report having perpetrated EV abuse and using DI tactics, than they were to report having been victimized by such abuse/tactics. Overall, $28.3 \%$ of women reported that they had perpetrated at 
least one act of physical violence, and $19.3 \%$ reported that they had perpetrated more than one act of violence against their romantic partner in the last year of their intimate relationship. By contrast, 19.3\% of women reported that their partners had perpetrated at least one act of violence against them, and $12.0 \%$ reported that their partners had perpetrated more than one act of violence against them in the last year of their intimate relationship. Women, then, were significantly more likely to report that they had perpetrated a violent act than that they had been victimized by a violent act.

Given large-scale studies, systematic reviews, and even government research have firmly demonstrated that female perpetration/male victimization are legitimate mental health concerns researchers are increasingly turning their focus to predictors and issues relevant treatment/intervention. It has only been relatively recently that increasing attention been devoted to examining characteristics and correlates of females who perpetrate IPV. That this is an important line of inquiry to pursue with female batterers is becoming increasingly evident. For instance, attachment styles and personality disorders among batterers are theoretically important in treatment; in fact, an association has been noted between personality disorders and violence severity in females (Renzetti, 1992). Further, results from Fortunata and Kohn's (2003) demonstrated that borderline or antisocial personality disorder traits were among significant predictors of lesbian intimate partner battering. For further consideration, readers are directed to Dutton's (2002) compiled extensive reviews on both male and female battering as associated with personality disorder traits.

Initial inquiry into the psychopathology of female intimate partner assaulters has focused on women in conflict with the law. Simmons, Lehmann, Cobb, \& Fowler (2005) compared court-referred male and female offenders and found that $71 \%$ of the females versus $26 \%$ of the males showed clinically significant elevations on at least one of the subscales measuring personality psychopathology. These women scored higher on the Histrionic, Narcissistic, and Compulsive subscales, and scored lower on the Dependent subscale. Goldenson, Geffner, Foster, and Clipson (2007) also examined offenders but used a femaleonly sample, comparing female offenders mandated to group treatment to women in a clinical control group (i.e., women in psychological treatment but who had not perpetrated violence). Using the MCMI III, these researchers found that the female offenders of intimate partner violence had higher relative elevations on the Antisocial, Borderline, and Dependent Subscales as compared to the clinical control group. Additionally, these researchers found that the offender group suffered from significantly more trauma symptomatology as compared to the clinical control group.

It seems apparent, then, that personality psychopathology is related to the perpetration of violence. In fact, in another study of women with a history of IPV, Ehrensaft, Cohen, and Johnson (2006) reported that personality disorders were more successful at predicting intimate violence than was gender. It is notable that as with several of the above-mentioned studies, the MCMI III was used. This is important as this measure has been known to over-predict personality psychopathology in batterers (Hart, Dutton, \& Newlove, 1993). As such, the current study explored personality psychopathology using the SCID II, which has been shown in certain populations to be more reliable than other measures such as the MCMI-II (Kennedy et al., 1995).

The aforementioned studies, then, seem to suggest that psy- chopathology has been implicated in, if not a principle explanation for, female perpetrated IPV. Further, from the research done to date, it also seems apparent that the presence of "cluster B” personality disorder traits, in particular, seems to feature prominently in those who perpetrate intimate partner violence. The "dramatic" cluster B disorders are characterized by traits such as negative affectivity, impulsivity, and poor behavioural control, amongst others. This cluster is made up of four disorders: narcissistic (characterized by grandiosity, need for attention and lack of empathy), histrionic (marked by excessive emotionality and attention seeking), borderline (described by instability in interpersonal relationships, self-image, and affect); and finally antisocial (characterized by an often blatant disregard for, and violation of, the rights of others; American Psychiatric Association, 2013). The implications for intimate partner conflict resolution are readily apparent when the core features of these disorders (maladjustments in affect, interpersonal relations, and behavioural control) are considered. In addition to a high prevalence of borderline personality features in a group of male court mandated treatment batterers, Dutton (2002) found that chronic trauma symptoms also had a role in the development of an "abusive personality".

It has also been found that women who are court mandated to attend violence intervention programs, as compared with women in the general population, may experience elevated levels of post-traumatic stress disorder (PTSD) symptoms (Goldenson, Geffner, Foster, \& Clipson, 2007; Stuart, Moore, Gordon, Ramsey, \& Kahler, 2006). As an association between PTSD symptoms and an increase in the likelihood of engaging in subsequent violent acts has been found in other samples (e.g., Pollock, 1999), this is certainly an important facet of violence perpetration in the domestic context. It is additionally apparent that, as is the case with males, identifying features of female who perpetrate IPV has important applied implications. These include aiding with violence risk assessment and prevention, treatment, and management of such offenders.

The main objective of the present study was to gather data on the occurrence of cluster B personality disorder traits, PTSD symptomology, nature of IPV in a non-clinical sample of female perpetrators of IPV. We expected that this population would present with more cluster B personality disorder traits, PTSD symptomology, more incidence and severity of IPV than a population that did not endorse a history of IPV.

\section{Method}

\section{Participants}

Participants included 136 female undergraduate students from a large university in western Canada. Inclusion criteria required that the women had been involved in a romantic relationship in which they perpetrated some form of violence on their male partner. The mean age of participants was 21.8 years $(S D=2.0$, range $=19-28)$ and the majority reported their ethnicity as Asian (64.4\%), followed by Caucasian (31.8\%), Canadian First Nations (2.3\%), and other (1.5\%). This is consistent with the student population composition of the university. As expected within an undergraduate sample, the level of education was relatively high. All participants had completed high school, $65.6 \%$ of the sample had completed at least some postsecondary education, and $0.7 \%$ had completed at least some portion of a graduate degree. When asked about their current relationship status the majority (81.4\%) reported being in a 
relationship currently, while $18.7 \%$ were single at the time of participation. Only $1.5 \%$ of the sample reported being married and $11.2 \%$ were in a common-law relationship.

\section{Procedure}

After the study received ethical approval the undergraduate participants were recruited using the university's psychology human subject pool. Advertisements were posted on the psychology student's bulletin board. These postings stated that participants must be female, and must have, at some point, been involved in an intimate relationship where they had inflicted some form of violence on their male partner. Participants were given two psychology credits for their participation, applicable to any first or second year psychology course in which they were enrolled.

The participants were ensured of the study's confidential nature via the consent form. In order to protect anonymity, they picked up the questionnaire packages from a box in a relatively traffic-free hallway of the psychology department. As part of a larger questionnaire package, participants in the present study were instructed to complete the following questionnaires in a quiet, private area, at their own pace, but all in one sitting: The Structured Clinical Interview for DSM Personality Disorders Questionnaire (SCID-II; First, Gibbon, Spitzer, Williams, \& Benjamin, 1997); the Conflict Tactics Scale (CTS; Straus, 1979); the Extrafamilial Violence Scale (EVS; Bodnarchuk, Kropp, Ogloff, Hart, \& Dutton, 1995); the Multidimensional Anger Inventory (MAI; Siegel, 1986); and the Impact of Event Scale (IES; Horowitz, Wilner, and Alvarez, 1979). The participants returned their completed questionnaire packages to a sealed drop-box at the same location, in order to protect anonymity.

\section{Measures}

Personality Disorders: The Structured Clinical Interview for DSM-IV Axis II Personality Disorders Self-Report (SCID-II$S R)$.

First et al.’s (1997) 119 yes/no items compose this questionnaire that assesses the DSM-IV diagnostic criteria for 11 personality disorders. A score is obtained on each personality disorder scale on the measure. Relatively little information exists to date on the reliability and validity of the DSM-IV version of the SCID-II (see Dreesen, Hildebrand, \& Arntz, 1998; First et al., 1997). Studies investigating these properties within the DSM-III-R (3rd ed., rev.; APA, 1987) version of the SCID-II have demonstrated adequate reliability and validity, and from this, its authors have reasoned similar psychometric properties of the DSM-IV version (First et al., 1995).

Dimensions of Anger Response: Multidimensional Anger Inventory $(M A I)$.

The Multidimensional Anger Inventory (Siegel, 1986) is a 38 item self-report scale assessing dimensions of anger response including the frequency (e.g., I tend to get angry more frequently than most people), duration (e.g., When I get angry, I stay angry for hours), magnitude (e.g., I often feel angrier than I think I should), mode of expression (e.g., When I am angry with someone, I take it out on whoever is around), hostile outlook (e.g., I am secretly quite critical of others), and range of anger-eliciting situations (e.g., I get angry when something blocks my plans), simultaneously. Participants rate each item on a scale from " 1 = this statement is completely undescriptive of you" to " 5 = this statement is completely descriptive of you". The MAI has been found to possess acceptable test-retest reliability $(r=.75)$ and high internal consistency (alpha $=.84$ and .89 for college students and male factory workers, respectively; Siegel, 1986).

Relationship Violence: The Conflict Tactics Scales (CTS).

The well-known Conflict Tactics Scales (Straus, 1979) comprise a 20 item self-report measure that assesses both the frequency and intensity in which romantic partners engage in verbal and physical techniques in the process of conflict resolution. The techniques, or tactics, are measured via four scales in this study: Reasoning (i.e., the use of rational discussion, argument and reasoning as a means to resolve conflict), Verbal Aggression (i.e., verbal aggression including, but not limited to, direct threats of harm and non-verbal acts used with the intension of hurting the recipient partner), and Violence (i.e., the use of physical force against the recipient partner) which was separated into minor and severe violence. These scales are comprised of lists of actions, ranging from those low in coerciveness to those highly coercive and aggressive. Participants responded on a seven point scale, from " 1 = never" to "7 = more than 20" times. The participants responded to questions regarding acts that they themselves had perpetrated, and those for which they had been the victim of an act of violence perpetrated by an intimate partner. Internal consistency reliability of the scales is in the acceptable range $(.70-.88)$, and numerous studies (see Straus, 1979; also see Archer, 1999) support its validity (but also see Schafer, 1996).

Post Traumatic Stress Symptoms: Impact of Event Scale (IES).

The Impact of Event Scale (Horowitz et al., 1979) is a 15item self-report measure of subjective distress experienced in the past seven days in relation to a particular experienced event. This scale assesses the frequency of experiencing symptoms of two core components of PTSD, intrusions and avoidance, over the past seven days. Ratings are given on a six-point Likert scale (" $0=$ not at all" to " $5=$ often"). The IES has high split half reliability $(r=.86)$, internal consistency (using Cronbach's Alpha, intrusion $=.78$, avoidance $=.82$ ), and test-retest reliability (.87; Horowitz et al., 1979). The IES is one of the most frequently used measures of post-traumatic stress (McDonald, 1997). It is also reliable in its ability to distinguish between those with and without PTSD (Arata, Saunders, \& Kilpatrick, 1991), despite being a self-report measure. The advantage the IES possesses in yielding a continuous measure of the frequency of both intrusive and arousal symptoms are that the presence of sub-clinical PTSD can be evaluated. Alternately, a number of different cut-off scores have been used with the IES, ranging from 19 (Horowitz, 1982) to 35 (Neal, Busuttil, \& Rollins, 1994). The present study used an IES cut-off of 28. This is approximately mid-range of previously suggested cutoff scores and is arguably a conservative cut-off for identifying PTSD symptoms.

\section{Results}

\section{Cluster B Personality Disorder Traits: Prevalence}

The prevalence rates for the presence of a cluster B personality disorder and the presence of a specific cluster B disorder are presented in Table 1. Also presented in the table are base rates for the prevalence of cluster B disorders in a comparison nonclinical Canadian university sample (Watson \& Sinha, 1998). 
Table 1.

Base rates of cluster B personality disorders, by type, in a non-clinical sample of female who perpetrate IPV and a non-clinical sample not selected for IPV.

Cluster B Narcissistic Histrionic Borderline Antisocial

\begin{tabular}{lccccc}
\multicolumn{5}{c}{ Cluster B } & Narcissistic \\
\hline $\begin{array}{l}\text { Undergraduate } \\
\text { students not } \\
\text { selected for IPV }\end{array}$ & $43.4 \%$ & $22.8 \%$ & $7.4 \%$ & $22.1 \%$ & $66.2 \%$ \\
$\begin{array}{l}\text { Undergraduate } \\
\text { students not } \\
\text { selected for IPV }\end{array}$ & $16.7 \%$ & $4.2 \%$ & $3.4 \%$ & $4.0 \%$ & $5.0 \%$ \\
\hline
\end{tabular}

As can be seen, the incidence of cluster B disorders in our sample of undergraduate women who identified themselves as having committed intimate violence against a male partner is substantially higher than was found in Watson and Sinha's sample of 1729 male and female undergraduates.

\section{Dimensions of Anger Response: Multidimensional Anger Inventory}

For the following analyses, one-way ANOVAs were calculated for each personality disorder category to compare women with and without the specific Axis II disorder. Analyses revealed that while women with narcissistic personality disorder traits displayed a significantly greater duration and frequency of anger response than non-narcissists $(F[1,124]=10.10, p$ $<.007)$, there were no significant differences between those with histrionic traits and those without histrionic traits $(F[1$, $124]=.01, p=.906)$. The women in our sample with borderline personality disorder traits also reported a significantly greater anger response than did women without borderline characteristics $(F[1,124]=6.91, p=.008)$, as did those with antisocial traits compared to those without elevated levels of such traits ( $F$ $[1,124]=21.45, p<.001)$.

\section{Relationship Violence: Conflict Tactics Scale}

Nature and Frequency of Abuse.

The following includes a description of the frequency of abuse perpetrated by women against their male partners, as measured by the CTS. The mean CTS total score was 49.61 $(\mathrm{SD}=17.20)$, and mean subscale scores were reasoning 26.76 ( $\mathrm{SD}=17.46)$, verbal aggression 24.24 (SD = 23.19), minor physical aggression 3.95 ( $\mathrm{SD}=8.26$ ), and severe physical aggression $3.14(\mathrm{SD}=7.25)$.

Participants with narcissistic personality disorder traits reported perpetrating significantly more minor physical violence against an intimate partner than did women without narcissistic traits $(F[1,134]=7.58, p=.006)$. There were no significant differences on any of the CTS subscales between those participants who displayed histrionic personality disorder traits and those who did not. Women with borderline personality disorder traits reported not only perpetrating more severe physical violence on an intimate partner $(F[1,130]=8.25, p=.007)$, but also reported more frequently being the victim of severe violence from their intimate partner $(F[1,130]=6.38, p=.012)$ than did women without borderline traits. Women with antisocial personality disorder traits reported perpetrating more minor physical intimate partner violence $(F[1,134]=4.40, p=.023)$, and more severe physical intimate partner violence $(F[1,130]$
$=7.84, p=.009)$ than did women without antisocial traits. In addition, the former group also reported being more often the recipients of reasoning tactics $(F[1,130]=4.34, p=.034$, and being victims of severe physical violence $(F[1,130]=12.68, p$ $<.001$ ) from their intimate partner.

\section{Post Traumatic Stress Symptoms: Impact of Event Scale}

In terms of reported PTSD symptoms, $72 \%$ of our female perpetrators either met or exceeded our selected cut-off for identifying the presence of PTSD on the IES. This base rate did not differ between those identified as meeting scoring threshold for any cluster B disorder and those who did not.

As illustrated in Table 2, bivariate Pearson r two-tailed correlations were calculated across the personality disorder categories on both subscales of the IES, intrusion and avoidance. Although no significant correlations were found between endorsement of narcissistic, histrionic, borderline, or antisocial personality disorder traits and the presence of intrusion symptoms, two significant correlations were found with avoidance symptoms. A higher endorsement of narcissistic and antisocial traits was significantly associated with a greater severity of reported avoidance symptoms $(r=.18, p=.045$, and $r=.19, p$ $=.037$, respectively). Significance was not reached in this domain with regards to either histrionic or borderline personality disorder traits.

\section{Discussion}

This study had two primary objectives. We sought to identify the prevalence of cluster $\mathrm{B}$ personality disorders in a nonclinical sample of self-identified female who perpetrate IPV. Additionally, we examined the associations between the incidence of these disorders and the women's self-reported anger responses, violence perpetration, and PTSD symptomatology.

The cluster B personality disorder prevalence rates found in the present study are notably high, especially when considered alongside the much lower rates of a comparable non-clinical university sample (Watson \& Sinha, 1998). In a growing number of studies investigating personality factors in female who perpetrate IPV such findings are increasingly observed. For example, in a recent study of female IPV, narcissistic, borderline, and antisocial personality disorders were among the most prevalent diagnoses (Spidel, Nicholls, Kendrick, Klein, \& Kropp, 2004). Further, a full one-third of the sample met criteria for three or more personality disorders. Consistent with Clift and Dutton's (2011) study of undergraduates, the Spidel et al. study had a similar finding with regards to the prevalence of borderline personality features. In this study borderline personality disorder was not only linked to violence but correlated strongly with severe physical violence. Certainly, it would be of

Table 2.

Pearson $r$ correlations between personality disorder trait endorsement and the IES subscales: Intrusion and avoidance.

\begin{tabular}{lcccc}
\hline & Narcissistic & Histrionic & Borderline & Antisocial \\
\hline $\begin{array}{l}\text { IES Intrusion } \\
\text { Subscale }\end{array}$ & .05 & .11 & .03 & .10 \\
$\begin{array}{l}\text { IES Avoidance } \\
\text { Subscale }\end{array}$ & $.19^{*}$ & .14 & .06 & $.19^{*}$ \\
\hline${ }^{*} p<.05$. & & & &
\end{tabular}


interest to compare the findings of our undergraduate sample to women who are in treatment for or are convicted of intimate partner violence across similar variables.

With the exception of women with histrionic traits, female who perpetrate IPV with cluster B personality disorder traits reported experiencing more frequent and severe anger responses than participants with no cluster B traits. These internal attributions of anger are hypothesized to be associated with outward displays of violence. Indeed, as compared to participants falling below threshold levels of each disorder, women demonstrating more narcissistic traits reported perpetrating more verbal aggression on the CTS, women scoring higher on borderline personality traits demonstrated more violence, and women scoring higher on antisocial traits demonstrated more violence and verbal aggression against intimate partners. The results suggest that treatments typically appropriate to male perpetrators and other populations of female disorders are likely also applicable to women who engage in violence tactics in romantic relationships. The need to pursue the study of personality features in female batterers is further emphasized through evidence that maternal inter-parental abuse has a more severe detrimental effect on children than paternal interparental abuse (Moretti, Penney, Obsuth, \& Odgers, 2007).

In terms of reported PTSD symptomatology, $72 \%$ of our female perpetrators met or exceeded a conservative cut-off for identifying the presence of PTSD. This base rate did not differ as a function of cluster B disorder traits. When compared to a $31 \%$ rate found in a non-clinical Canadian university sample (Greaves, 2005), and a 36\% rate found in a sample of child sexual abuse victims (McLeer et al., 1998), it is clear that the present sample's rate trauma symptoms is quite substantial. This does indeed support previous findings of female batterer trauma symptomatology (Abel, 2001). Specifically, results suggest that both narcissistic and antisocial personality traits are associated with experiencing avoidance PTSD symptoms in relation to intimate partner violence perpetration. If certain avoidance strategies are perpetuating affective and cognitive avoidance of the event, this will likely hamper treatment efforts. Full emotional realization is often an integral step for resolution in PTSD therapy (see Foa \& Hearst-Ikeda, 1996), and therefore must be addressed with such clients. As previously mentioned, an association between PTSD and violence perpetration as been found in other samples (e.g., Jakupcak \& Tull, 2005; Pollock, 1999; Stuart, Moore, Gordon, Ramsey, \& Kahler, 2006; Taft et al., 2005). Together, these results suggest that further investigation should focus on narcissistic and antisocial batterers in light of the incidence of reported physical violence both within and outside of intimate relationships. It also highlights the need for awareness of trauma within this population.

Limitations to this preliminary study include the use of selfreport measures, including our personality disorder measure. Accordingly, future research should include structured interviews to obtain a more accurate diagnostic picture and would allow for further investigation into issues such as co-morbidity. It is also not uncommon for participants to underreport violence perpetration, especially when responding to the CTS (Straus, 1979; Dutton \& Nicholls, 2005). Our results then may reflect conservative estimates of intimate partner violence. This study did not include corroboration from the participants' partners or contextual information, therefore, in addition to being without a means of assessing "ground truth", we also lack information on which partner was initiating the violence, if it was purely one sided, or if the women were in fact perpetrating violence in the context of self-defense. The best predictor of perpetrating intimate partner violence is having a violent partner (Malik, Sorenson, \& Anesheusel, 1997; White, Merrill, \& Koss, 2001), and indeed those women displaying narcissistic, borderline and antisocial traits did report more minor and severe violence victimization than did those without the personality disorders. Thus treatment that reduces women's use of abusive relationship behaviors is quite likely to increase their safety as well as reducing associated implications for their partner and any children. Also, this study instructed participants to respond with respect to one relationship in which they had perpetrated violence. We plan to continue along this line of inquiry in terms of multiple instances of violence; that is, to identify patterns of perpetration across multiple relationships. Lastly, the results of our investigation can be generalized only to violence perpetrated by non-clinical populations of women in heterosexual relationships.

One of the main implications of these results is that female intimate partner assaulters are not a homogeneous group and therefore should be treated and managed, accordingly. Personality features such as cluster B disorders should be considered in female perpetrators as those who display certain personality disorder traits report differences in anger response, violence severity, and trauma/stress reactions. Along with assessing for trauma symptomatology, assessment of personality disorder features would reveal pathological interpersonal and coping styles that might otherwise be overshadowed by the battering behaviour. Targeting these features along with the maladaptive behaviour may indeed be the only way to effect lasting change. For example, dialectical behavior therapy (Linehan, 1993), a cognitive-behavioral intervention for borderline personality disorder, could alter negative affective responses to interpersonal situations and teach alternative, more adaptive coping styles that might result in a reduction in violence against intimate partners (Waltz, Babcock, Jacobson, \& Gottman, 2000).

Given the high prevalence of personality disorders and PTSD in this population it would also be of interest to investigate the prevalence of childhood abuse in a similar sample to one here for a couple reasons. One, IPV is consistently associated with high rates of depression, anxiety disorders (especially PTSD), sleep disorders, phobias and panic disorder, antisocial personality disorder and borderline personality disorders, psychosomatic disorders, and suicidal behaviour and self-harm (see Jordan et al., 2010). Depression and PTSD are the most prevalent mental health impacts of IPV, with considerable comorbidity of the two disorders (Jordan et al., 2010, Basile et al., 2004). Two, there is now substantial evidence linking child sexual abuse and child physical abuse to a range of mental health problems in childhood (Spataro, Mullen, Burgess, Wells, \& Moss, 2004). Child abuse has also been shown to been associated with most adult disorders, including: depression, anxiety disorders, PTSD, eating disorders, substance abuse, sexual dysfunction, personality disorders and dissociative disorders, as well as suicidality (Bushnell, Wells, \& Oakley-Browne, 1992; Fergusson, Horwood, \& Lynesky, 1996; Kendler et al., 2000; Mullen, Martin, Anderson, Romans, \& Herbison, 1993). There future studies should evaluate the history of childhood abuse when studying perpetrators of IPV.

To conclude, one point must certainly be stressed: the aim of this research is not to pathologize women's behaviour, but to emphasize the need for an awareness of gender inclusivity at 
the various levels of intervention as one of many necessary efforts to improve the health and well-being of families (e.g., see Nicholls \& Hamel, 2005; Hamel \& Nicholls, 2007). Mental health practitioners treating women who have IPV have a growing number of studies to guide them in developing effective treatments. Investigating personality and inter-personal issues in female intimate partner assaulters will greatly assist in these efforts. At a more basic level, there is still a need for recognition of domestic violence perpetration by females and the victimization of males. Batterer interventions have not kept pace with existing empirical findings (Babcock, Canady, Graham, \& Schart, in press; Babcock, Green, \& Robie, 2004; Dutton, in press), particularly with regard to the value of family interventions and couples counseling (Hamel \& Nicholls, in press). Through continued empirical study great strides will be made towards accurate diagnosis, development and implementation of adequate management strategies as well as tailored treatment programs for these perpetrators and the recipients of their violence.

\section{REFERENCES}

Abel, E. M. (2001). Comparing the social service utilization, exposure to violence, and trauma symptomology of domestic violence female "victims" and female "batterers". Journal of Family Violence, 16, 401-420. http://dx.doi.org/10.1023/A:1012276927091

American Psychiatric Association (1987). Diagnostic and statistical manual of mental disorders (3rd ed., Revised (DSM-III-R)). Washington DC: American Psychiatric Press.

American Psychiatric Association (1994). Diagnostic and statistical manual of mental disorders (4th ed.). Washington DC: American Psychiatric Press.

Arata, C. M., Saunders, B. E., \& Kilpatrick, D. G. (1991). Concurrent validity of a crime-related post-traumatic stress disorder scale for women with the symptom checklist-90-revised. Violence and Victims, 6, 191-199.

Archer, J. (1999). Assessment of the reliability of the conflict tactics scales: A meta-analytic review. Journal of Interpersonal Violence, 14, 1263-1289. http://dx.doi.org/10.1177/088626099014012003

Archer, J. (2000). Sex differences in aggression between heterosexual partners: A meta-analytic review. Psychological Bulletin, 126, 651680. http://dx.doi.org/10.1037/0033-2909.126.5.651

Archer, J. (2004). Sex differences in aggression in real-world settings: A meta-analytic review. Review of General Psychology, 8, 291-322. http://dx.doi.org/10.1037/1089-2680.8.4.291

Babcock, J. C., Canady, B., Graham, K., \& Schart, L. (2007). The evolution of battering interventions: From the Dark Ages into the Scientific Age. In J. Hamel, \& T. L. Nicholls (Eds.), Family interventions in domestic violence: A handbook of gender-inclusive theory and treatment (pp. 215-244). London: Springer.

Babcock, J. C., Green, C. E., \& Robie, C. (2004). Does batterer's treatment work? A meta-analytic review of domestic violence treatment. Clinical Psychology Review, 23, 1023-1053. http://dx.doi.org/10.1016/j.cpr.2002.07.001

Bodnarchuk, M. A., Kropp, P. R., Ogloff, J. R. P., Hart, S. D., \& Dutton, D. G. (1995). Predicting cessation of intimate assaultiveness after group treatment. Ottawa: Health Canada.

Bushnell, J., Wells, J., \& Oakley-Browne, M. (1992). Long-term effects of intrafamilial sexual abuse in childhood. Acta Psychiatrica Scandinavica, 85, 136-142. http://dx.doi.org/10.1111/j.1600-0447.1992.tb01458.x

Clift, R. J. W., \& Dutton, D. G. (2011). The abusive personality in women in dating relationships. Partner Abuse, 2, 166-189. http://dx.doi.org/10.1891/1946-6560.2.2.166

Desmarais, S. L., Reeves, K. A., Nicholls, T. L., Telford, R. P., \& Fiebert, M. S. (2012a). Prevalence of physical violence in intimate relationships, Part 2: Rates of male and female perpetration Partner Abuse, 3, 170-198.
Desmarais, S. L., Reeves, K. A., Nicholls, T. L., Telford, R. P., \& Fiebert, M. S. (2012b). Prevalence of physical violence in intimate relationships, Part 1: Rates of male and female victimization. Partner Abuse, 3, 140-169. http://dx.doi.org/10.1891/1946-6560.3.2.140

Dreesen, L., Hildebrand, M., \& Arntz, A. (1998). Patient-informant concordance on the Structured Clinical Interview for DSM-III-R personality disorders (SCID-II). Journal of Personality Disorders, 12, 149-161. http://dx.doi.org/10.1521/pedi.1998.12.2.149

Dutton, D. G. (2002). Personality dynamics of intimate abusiveness. Journal of Psychiatric Practice, 8, 216-228. http://dx.doi.org/10.1097/00131746-200207000-00005

Dutton, D. G. (2002). The abusive personality: Violence and control in abusive relationships (2nd ed.). New York: Guilford.

Dutton, D. G. (2007). Thinking outside the box: Gender and courtmandated therapy. In J. Hamel, \& T. L. Nicholls (Eds.), Family interventions in domestic violence: A handbook of gender-inclusive theory and treatment. Under contract with Springer.

Dutton, D. G., \& Nicholls, T. L. (2005). A critical review of the gender paradigm in domestic violence research and theory: Part I-Theory and data. Aggression and Violent Behavior, 10, 680-714. http://dx.doi.org/10.1016/j.avb.2005.02.001

Dutton, D. G., Nicholls, T. L., \& Spidel, A. (2005). Female perpetrators of intimate abuse. Journal of Offender Rehabilitation, 41, 1-31. http://dx.doi.org/10.1300/J076v41n04_01

Ehrensaft, M., Cohen, P., \& Johnson, J. (2006). Development of personality disorder symptoms and the risk for partner violence. Journal of Abnormal Psychology, 115, 474-483. http://dx.doi.org/10.1037/0021-843X.115.3.474

Fergusson, D., Horwood, L., \& Lynskey, M. (1996). Childhood sexual abuse, and psychiatric disorder in young adulthood. Journal of America Academy of Child \& Adolescent Psychiatry, 35, 1356-1374.

First, M. B., Gibbon, M., Spitzer, R. L., Williams, B. W., \& Benjamin, L. S. (1997). Structured clinical interview for DSM-IV axis II personality disorders self-report. New York: Biometrics Department, New York State Psychiatric Institute.

First, M. B., Spitzer, R. L., Gibbon, M., Williams, J. B. W., Davies, M., Borus, J. et al. (1995). The structured clinical interview for DSMIII-R personality disorders (SCID-II). Part II: Multi-site test-retest reliability study. Journal of Personality Disorders, 9, 92-104. http://dx.doi.org/10.1521/pedi.1995.9.2.92

Foa, E. \& Hearst-Ikeda, D. (1996). Emotional dissociation in response to trauma. In L. K. Michelson, \& W. Ray (Eds.), Handbook of dissociation: Empirical and clinical perspectives. New York: Plenum Press.

Fortunata, B., \& Kohn, C. (2003). Demographic, psychosocial and personality characteristics of lesbian batterers. Violence \& Victims, 18, 557-568. http://dx.doi.org/10.1891/vivi.2003.18.5.557

Goldenson, J., Geffner, R., Foster, F., \& Clipson, C (2007). Violence and Victims, 22, 532-545. http://dx.doi.org/10.1891/088667007782312186

Greaves, C. (2005). Phenomenological characteristics of autobiographical event memory. Unpublished Master's Thesis, Simon Fraser University, Burnaby, British Columbia, Canada.

Hamel, J., \& Nicholls, T. L. (2007). Family interventions in domestic violence: A handbook of gender-inclusive theory and treatment. Under contract with Springer.

Hart, S., Dutton, D., \& Newlove, T. (1993). The prevalence of personality disorders among wife assaulters. Journal of Personality Disorders, 7, 329-341. http://dx.doi.org/10.1521/pedi.1993.7.4.329

Hines, D. A., \& Douglas, E. (2010). Intimate terroism by women towards men: Does it exist? Journal of Aggression, Conflict and Peace Research, 2, 36-56. http://dx.doi.org/10.5042/jacpr.2010.0335

Horowitz, M. J. (1982). Stress response syndromes and their treatment. In L. Goldberger, \& S. Breznitz (Eds.), Handbook of stress: Theoretical and clinical aspects (pp. 711-732). New York: Free Press.

Horowitz, M. J., Wilner, H., \& Alvarez, W. (1979). Impact of Event Scale: A measure of subjective distress. Psychosomatic Medicine, 41, 209-218.

Jakupcak, M., \& Tull, M. T. (2005). Effects of trauma exposure on anger, aggression, and violence in a nonclinical sample of men. Violence and Victims, 20, 589-598. 
Jordan, B. K., Marmar, C. R., Fairbank, J. A., Schlenger, W. E., Kulka, R. A., Hough, R. L. et al. (1992). Problems in families of male Vietnam veterans with posttraumatic stress disorder. Journal of Consulting \& Clinical Psychology, 60, 916-926.

http://dx.doi.org/10.1037/0022-006X.60.6.916

Linehan, M. M. (1993). Cognitive-behavioral treatment of borderline personality disorder. New York: Guilford Press.

Magdol, L., Moffitt, T. E., Caspi, A., Newman, D. L., Fagan, J., \& Silva, P. A. (1997). Gender differences in partner violence in a birth cohort of 21 year olds: Bridging the gap between clinical and epidemiological approaches. Journal of Consulting and Clinical Psychology, 65, 68-78. http://dx.doi.org/10.1037/0022-006X.65.1.68

Malik, S., Sorenson, S., \& Anesheusel, C. (1997). Community and dating violence among adolescents: Perpetration and victimization. Journal of Adolescent Health, 21, 291-302. http://dx.doi.org/10.1016/S1054-139X(97)00143-2

Marshall, L. L. (1992). Development of the severity of violence against women scales. Journal of Family Violence, 7, 103-121. http://dx.doi.org/10.1007/BF00978700

McDonald, A. S. (1997). Factor structure of the impact of events scale in a non-clinical sample. Personality and Individual Differences, 23, 419-424.

McLeer, S., Dixon, J. F., Henry, D., Ruggerio, K., Escovitz, K., Niedda, T. et al. (1998). Psychopathology in non-clinically referred sexually abused children. Journal of the American Academy for Child and Adolescent Psychiatry, 37, 1326-1333. http://dx.doi.org/10.1097/00004583-199812000-00017

Moretti, M. M., Penney, S., Obsuth, I., \& Odgers, C. (2007). Family lessons in attachment and aggression: The impact of interparental violence on adolescent adjustment. In J. Hamel, \& T. L. Nicholls (Eds.), Family interventions in domestic violence: A handbook of gender-inclusive theory and treatment. Under contract with Springer.

Mullen, P. E., Martin, J. L., Anderson, J. C., Romans, S. E., \& Herbison, G. P. (1993). Childhood sexual abuse and mental health in adult life. British Journal of Psychiatry, 163, 721-732. http://dx.doi.org/10.1192/bjp.163.6.721

Neal, L. A., Busuttil, W., \& Rollins, J. (1994). Convergent validity of measures of post-traumatic stress disorder in a mixed military and civilian population. Journal of Traumatic Stress, 7, 447-455. http://dx.doi.org/10.1002/jts.2490070310

Nicholls, T. L., \& Hamel, J. (in press). Intimate partner violence. In P. Zapf \& B. Cutler (Eds.), American psychological association handbook of forensic psychology. Washington DC: American Psychological Association.

O’Keefe, N. K., Brockopp, K., \& Chew, E. (1986). Teen dating violence. Social Work, 31, 465-468.

Pollock, P. H. (1999). When the killer suffers: Post-traumatic stress reactions following homicide. Legal and Criminological Psychology, 4, 185-202. http://dx.doi.org/10.1348/135532599167842

Renzetti, C. M. (1992). Violent betrayal: Partner abuse in lesbian relationships. Newbury Park, CA: Sage.

Schafer, J. (1996). Measuring spousal violence with the conflict tactics scale: Notes on reliability and validity issues. Journal of Inter- personal Violence, $11,572-585$

http://dx.doi.org/10.1177/088626096011004008

Siegel, J. M. (1986). The multidimensional anger inventory. Journal of Personality and Social Psychology, 51, 191-200. http://dx.doi.org/10.1037/0022-3514.51.1.191

Simmons, C., Lehmann, P., Cobb, N., \& C., Fowler (2005). Personality profiles of women and men arrested for domestic violence: An analysis of similarities and differences. In F. Buttell, \& M. Carney (Eds.), Women who perpetrate relationship violence (pp. 63-83). New York: Haworth Press.

Spidel, A., Nicholls, T., Kendrick, K., Klein, C., \& Kropp, R. P. (2004). Characteristics of female intimate partner assaulters. Paper presented at the annual meeting of the International Association of Forensic Mental Health Services, Miami, FL.

Steinmetz, S. K. (1977-1978). The battered husband syndrome. Victimology, 2, 499-509.

Straus, M. A. (1979). Measuring intrafamily conflict and violence: The conflict tactics scale (CTS). Journal of Marriage and the Family, 41, 75-88. http://dx.doi.org/10.2307/351733

Straus, M. A. (1999). The controversy over domestic violence by women: A methodological, theoretical, and sociological of science analysis. In X. B. Arriaga, \& S. Oskamp (Eds.), Violence in intimate relationships (pp. 17-44). Thousand Oaks, CA: Sage. http://dx.doi.org/10.4135/9781452204659.n2

Straus, M. A., \& Gelles, R. J. (1990). Physical violence in American families: Risk factors and adaptations to violence in 8,145 families. New Brunswick, NJ: Transaction.

Stuart, G. L., Moore, T. M., Gordon, K. C., Ramsey, S. E., \& Kahler, C. W. (2006). Psychopathology in women arrested for domestic violence. Journal of Interpersonal Violence, 21, 376-389. http://dx.doi.org/10.1177/0886260505282888

Taft, C. T., Pless, A. P., Stalans, L. J., Koenen, K. C., King, L. A., \& King, D. W. (2005). Risk factors for partner violence among a national sample of combat veterans. Journal of Consulting and Clinical Psychology, 73, 151-159. http://dx.doi.org/10.1037/0022-006X.73.1.151

Thompson, E. H. (1991). The maleness of violence in dating relationships: An appraisal of stereotypes. Sex Roles, 24, 261-278. http://dx.doi.org/10.1007/BF00288301

Waltz, J., Babcock, J. C., Jacobson, N. S., \& Gottman, J. M. (2000). Testing a typology of batterers. Journal of Consulting and Clinical Psychology, 68, 658-669. http://dx.doi.org/10.1037/0022-006X.68.4.658

Watson, D. C., \& Sinha, B. K. (1998). Comorbidity of DSM-IV personality disorders in a nonclinical sample. Journal of Clinical Psychology, 54, 773-780. http://dx.doi.org/10.1002/(SICI)1097-4679(199810)54:6<773::AID-J CLP3>3.0.CO;2-I

White, J. W., Merrill, L. L., \& Koss, M. (2001). Predictors of premilitary courtship violence in a Navy recruit sample. Journal of Interpersonal Violence, 16, 910-927.

http://dx.doi.org/10.1177/088626001016009004 